\title{
Reforming respiratory outpatient services: a before-and- after observational study assessing the impact of a quality improvement project applying British Thoracic Society criteria to the discharge of patients to primary care
}

\author{
*Alice M Turner, ${ }^{1,2}$, Satinder Kaur Dalay², Ambika Talwar², Catherine Snelson², \\ Rahul Mukherjee ${ }^{2}$ \\ ${ }^{1}$ University of Birmingham, QEHB Research Laboratories, QEHB, Birmingham, UK
${ }^{2}$ Department of Respiratory Medicine, Birmingham Heartlands Hospital, Bordesley Green East, Birmingham, UK
}

Originally received 28th September 2012; re-submitted 2nd November 2012; revised 3rd December 2012; accepted 9th December 2012; online 25th February 2013

\begin{abstract}
Background: Secondary care physicians caring for people with long-term conditions (LTCS) are under increasing pressure to discharge long-term follow-up patients to primary care. In respiratory medicine, the 2008 British Thoracic Society (BTS) statement on criteria for specialist referral, admission, discharge, and follow-up for adults with respiratory disease remains the only available basis for this dialogue. There is widespread concern about reforming outpatient clinics to meet these demands and the impact of discharging people with respiratory LTCs to primary care.

Aims: To examine the impact of implementing BTS guidance on secondary care follow-up of patients with respiratory disease.

Methods: We undertook a clinic reform project, which included one-stop medical reviews, providing more open access appointments, and implementing the BTS criteria. The impact on patients was assessed by patient survey, and the impact on GPs was assessed by an analysis of referral patterns pre- and post-reform.

Results: There was a significant improvement in commissioner-mandated performance through reduction in follow-up ( $p=0.006)$ and the unscheduled hospital admission rate decreased significantly $(p=0.021)$. However, many patients were dissatisfied with the process and re-referral rates rose.

Conclusions: Our findings suggest that the delivery of a responsive service capable of sustainable management of respiratory LTCs can be achieved using the BTS criteria. It seems to be efficacious within secondary care, increasing the quality and value of the clinic activity, although hidden impacts on primary care will require further prospective studies.

(C) 2013 Primary Care Respiratory Society UK. All rights reserved.

AM Turner et al. Prim Care Respir J 2013; 22(1): 72-78

http://dx.doi.org/10.4104/pcrj.2013.00013
\end{abstract}

Keywords chronic obstructive pulmonary disease, healthcare delivery, long-term conditions

The full version of this paper, with online appendix,

is available online at www.thepcrj.org

\section{Introduction}

The financial structure and organisation of the National Health Service (NHS) in England is undergoing huge transformation. Primary care trusts (PCTs) have been abandoned, with the creation of general practitioner commissioning consortia (CCGs) acting as their replacement. ' General practitioners (GPs) are under pressure to reduce the number of secondary care follow-up appointments in future due to the increasing proportion of elderly people with chronic health problems, and consequent clinical and financial burden on the NHS. This imbalance between capacity and demand is not unique to the UK, although the financial set-up of the NHS tends to force efficiency drives and therefore make the problem more apparent. Models of care proved to offer value for money will become necessary in all health economies as the population ages.

\footnotetext{
* Corresponding author: Alice Turner, Clinician Scientist and Honorary Consultant Physician, Queen Elizabeth Hospital Research Laboratories, Mindelsohn Way, Birmingham, B15 2WB, UK. Tel: +44 (0)7825 683519 E-mail: a.m.wood@bham.ac.uk
} 
CCG leaders have an opportunity to lead the way worldwide by commissioning services that deliver both efficiency and quality, perhaps choosing not to purchase from providers whose services cannot deliver on both counts.

In respiratory medicine, much of the management of long-term conditions (LTCS) such as chronic obstructive pulmonary disease (COPD) is already taken on by community health professionals, but others such as interstitial lung disease are usually kept under hospital follow-up. This may be due to their rarity, a perception that GPs may not be experienced enough to manage them well, or a lack of access to appropriate monitoring procedures such as full lung function testing. Nevertheless, the health economy may not be able to sustain hospital follow-up of all such patients in future. A robust system to guide safe discharge is therefore needed to create sustainable services. The British Thoracic Society (BTS) statement on criteria for specialist referral, admission, discharge, and follow-up for adults with respiratory disease ${ }^{2}$ remains the only available basis for this dialogue in our specialty (see Box 1). Other strategies such as Hospital Outpatient Treatment (HOT) respiratory clinics, ${ }^{3}$ which offer rapid access appointments and aim to treat patients on the day of attendance, may speed up diagnosis but will not remove the need for discharge from specialist care.

The financial measures imposed locally at the inception of this study required us to find a way to rationalise the number of patients seen in our clinics, which would inevitably mean discharging more patients to primary care. We wished to do this in as evidence-based a manner as possible and therefore implemented the BTS criteria ${ }^{2}$ within our general respiratory clinics. We measured the impact of clinic discharge by the hospital admission rate pre- and post-reform, and the impact on patients and primary care by a patient satisfaction survey and an analysis of the proportion of patients referred back to our care within 18 months. Here we report the results of this service improvement intervention.

\section{Methods}

\section{Setting, planning and study design}

This is an observational study of a quality improvement project reported according to the SQUIRE checklist (see Appendix 1, available online at www.thepcrj.org). A retrospective analysis of patients attending all general respiratory clinics at Birmingham Heartlands Hospital, a large inner city teaching hospital, was conducted in July 2010 using the medical notes. All notes review was undertaken only by staff involved in the care of patients in those clinics, ensuring that confidential data were not viewed inappropriately. Patients whose primary diagnosis was obstructive sleep apnoea (OSA) or cystic fibrosis (CF) were excluded, in line with PCT contracts at the time. A second analysis was undertaken from October to December 2010 following the application of BTS criteriadriven reform within two general respiratory clinics, ${ }^{2}$ and was longer in order to ensure sufficient data capture. The impact of the process was assessed 6 and 18 months later. This is summarised in Figure 1.

\section{Clinic reform process}

In the 6 weeks after initial notes review, clinic structures were changed to allow booking of fewer follow-up patients and notes for

\section{Box 1. BTS criteria for common conditions}

\section{Asthma}

\section{Discharge back to primary care}

- Patients who have an established diagnosis of stable asthma

- Patients with well controlled hyperventilation syndrome

- Occupational asthma with stable disease when patients have been successfully removed from the causative agents

- Stable disease in patients who have been treated for sinusitis or gastro-oesophageal reflux

\section{Follow-up by specialist respiratory clinic and reviewed every}

\section{2-3 months}

- Patients with repeated exacerbations

- Patients with severe disease requiring multiple pharmacological agents

- Patients with brittle asthma

- Patients who have had a near fatal asthma attack

Follow-up by specialist respiratory clinic even if stable asthma and reviewed every 4-6 months

- Patients receiving treatment with novel treatments (e.g. monoclonal antibodies)

- Patients with stable prednisolone-dependent asthma

- Patients with stable asthma on any other immunosuppressant

- Symptomatic patients with concomitant bronchiectasis

- Patients who wish to be treated by a specialist with the agreement of the GP and specialist

\section{COPD}

Discharge back to primary care

- Patients with stable symptoms in whom the diagnosis of COPD is firmly established

- Patients who express a wish to be followed up in primary care after advice from the GP and specialist

Follow-up by specialist respiratory clinic

- Those with frequent exacerbations

- Patients on long-term oxygen therapy or nebulised bronchodilators

- Patients awaiting confirmation of diagnoses other than COPD

- Patients referred for lung transplantation or lung volume reduction surgery

- Patients who express a wish to be followed up by respiratory specialists after advice from the GP and specialist

- Patients with chronic hypoxia who are not yet on long-term oxygen therapy 
Figure 1. Structure of the clinic reform process and evaluation. The diagram shows the timeline on the left and actions occurring at each time point in the flow diagram to the right, together with relevant numbers of patients. Light grey boxes show the pre-reform aspects of evaluation while darker grey boxes below the reform process show post-reform actions

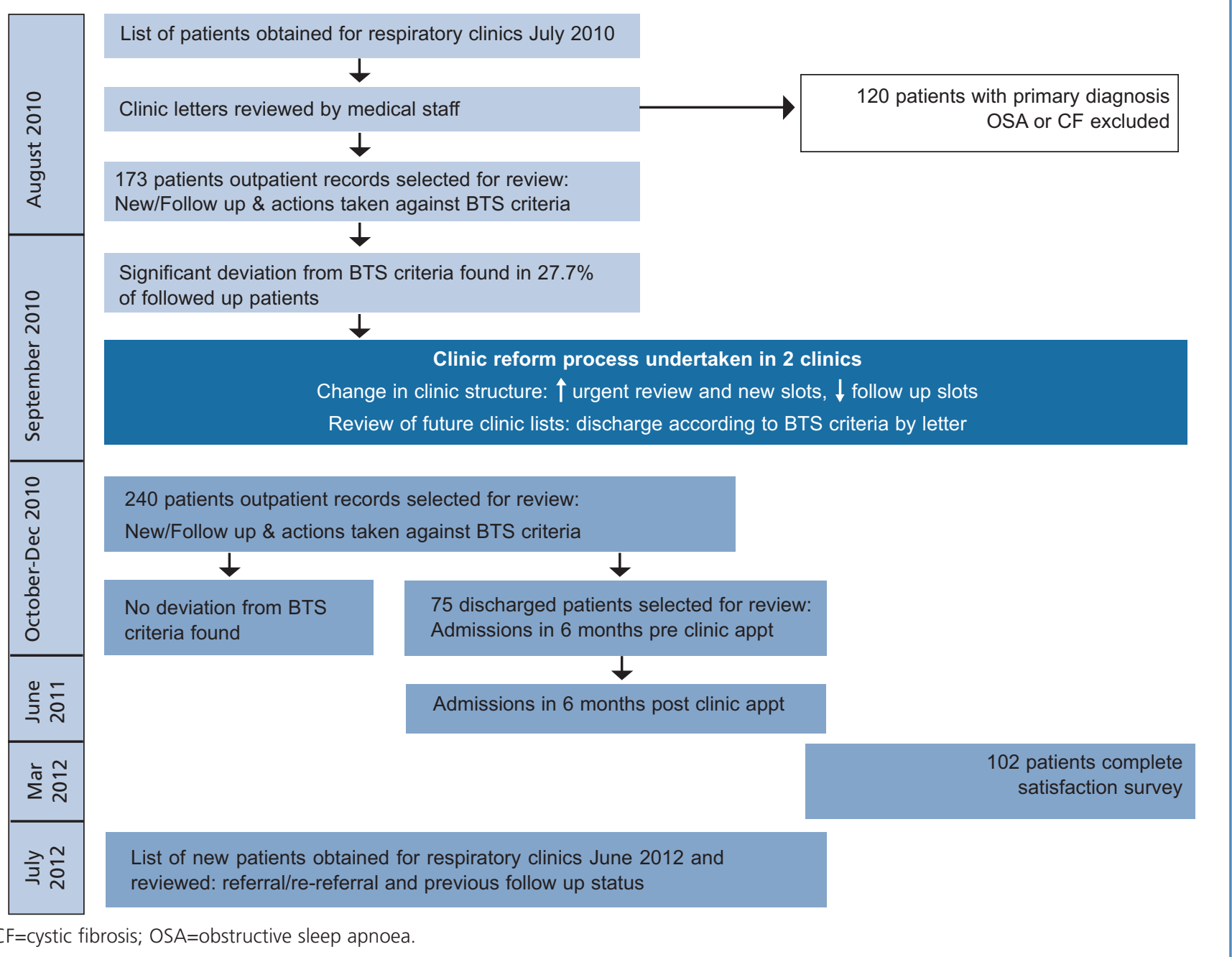

future follow-up appointments were reviewed to determine if patients could be discharged to the GP with advice. If they met the discharge criteria, patients were sent a letter indicating it was safe for their GP to manage their condition; a standard PCT approved letter was used unless there was a clinical reason to do otherwise. A safety net was set up to allow GPs to re-book patients without a new referral if they felt hospital follow-up was clinically indicated. Patients were also given a telephone number to re-book if they wished to discuss their future management and were given written self-management advice where indicated. Clinics also used six rapid access review slots (akin to a HOT clinic $^{3}$ ) and more open access appointments were made available to patients discharged from clinic. The second study period was timed to allow all the above to have been implemented before second data collection.

\section{Impact of clinic reform}

The validity of the reform process was checked by comparing the ratio of BTS appropriate and inappropriate discharges before and after the intervention.

The wider impact was assessed in three ways: (1) impact on hospital admissions; (2) impact on patient satisfaction; and (3) impact on referral rates to our clinics. To assess the bearing of outpatient discharges on acute medical services, unscheduled respiratory-related hospital admission rates for patients discharged from pilot clinics in the 6 months following the date of the clinic were compared with the preceding 6 months. After the initial intervention, we conducted a prospective study of patients' opinions of the new clinic style using a 5-point Likert-style questionnaire specifically assessing whether they felt regular outpatient review was helpful and whether they were comfortable with open access to hospital clinics or community follow-up. Finally, to give an indication of whether the process was adversely impacting on GPs, we looked at the proportion of patients who were being referred back after a prior clinic discharge, comparing this between new patients in the pre-intervention sample period 
and new patients from all general clinics 18 months after implementation of the reform (June 2012). This time period was chosen as it was thought likely to pick up issues arising in all previously followed-up patients, even those whose reviews were scheduled annually. We also requested specific feedback from local GPs on the set-up of reformed clinics.

\section{Statistical analyses}

Statistical analysis was undertaken in SPSS Version 16.0. Normally distributed data are reported as mean (standard error of mean, SEM) and non-normal data as median (interquartile range). Comparisons of discharged and non-discharged patients were carried out using the $\chi 2$ and Mann-Whitney tests, while admission rates were compared using the paired test. Patient opinions are reported as raw data only. Comparisons of new referrals pre- and post-reform were carried out using the $\chi 2$ test, selecting those never seen by respiratory medicine and those referred back after previous discharge.

\section{Results}

\section{Prior to clinic reform}

Three hundred and twenty-five patients were scheduled to attend clinic, of whom 32 did not attend and 120 were excluded due to OSA or CF. The ratio of new/follow-up patients was 29/144 (1 new to 5 follow-up patients) - see Table 1 for patient demographics and diagnoses.

The majority of appointments were follow-up after a previous clinic review ( $n=142)$. Twelve post-discharge reviews, $11 \mathrm{GP}$ referrals, and eight other new patient referrals were also seen. Seventy-nine patients were seen by a consultant and 94 by a respiratory registrar; discharge rates were 18/79 and 10/94, respectively, suggesting a strong trend towards discharge being more likely if seen by a more senior clinician $(p=0.067)$. Table 2 shows that discharge rates from clinic and compliance with BTS guidance was low before reform, thus confirming that a change in clinic practice was needed.

\section{After clinic reform}

Two hundred and sixty-three suitable patients were scheduled to
Table 1. Patient demographics and diagnoses

\begin{tabular}{llll} 
& $\begin{array}{l}\text { Pre-reform } \\
(\mathrm{n}=173)\end{array}$ & $\begin{array}{l}\text { Post-reform } \\
(\mathrm{n}=240)\end{array}$ & $\mathrm{p}$ Value \\
\hline Age & $\begin{array}{l}61.02 \\
(42.5-72.0)\end{array}$ & $\begin{array}{l}60.96 \\
(1.94)\end{array}$ & 0.851 \\
\hline Male sex & $79(45.7)$ & $124(51.7)$ & 0.231 \\
\hline Respiratory diagnosis & & & 0.063 \\
\hline Asthma & 52 & 50 & \\
\hline COPD & 41 & 34 & \\
\hline Bronchiectasis & 28 & 50 & \\
\hline $\begin{array}{l}\text { Community-acquired } \\
\text { pneumonia }\end{array}$ & 6 & 14 & \\
\hline $\begin{array}{l}\text { Lung cancer } \\
\text { Tuberculosis }\end{array}$ & 7 & 10 & \\
\hline $\begin{array}{l}\text { Interstitial lung disease } \\
\text { Action at end of clinic }\end{array}$ & 18 & 31 & \\
\hline $\begin{array}{l}\text { Discharged back to primary } \\
\text { care }\end{array}$ & 28 & 58 & \\
\hline $\begin{array}{l}\text { Discharged with open access } \\
\text { Transferred to another }\end{array}$ & 1 & 17 & \\
\hline $\begin{array}{l}\text { consultant } \\
\text { Remained under follow-up }\end{array}$ & 143 & 4 \\
\hline
\end{tabular}

The table shows the patients who attended pre- and post-clinic reform; patients who did not attend or were excluded due to their underlying diagnosis are not shown

Age is shown as median (IQR) pre reform due to non-normal distribution, and mean (SEM) post reform. COPD=chronic obstructive pulmonary disease

attend clinic; 23 did not attend. The ratio of new to follow-up patients improved significantly $\left(111 / 129 ; p<1 \times 10^{-6}\right)$, such that it approached one new patient for every follow-up. During the clinics, significantly more patients were discharged (28/173 vs. 75/240, $\mathrm{p}=0.006) ; 17$ were given open access after discharge. A trend towards a change in the range of conditions was seen $(p=0.063)$.

Effect on admissions

Unscheduled hospital admission rates for patients discharged post-

Table 2. Adherence to British Thoracic Society (BTS) guidance for discharge

\begin{tabular}{|c|c|c|c|c|c|c|}
\hline \multirow[t]{2}{*}{ Disease } & \multicolumn{3}{|l|}{ Pre-reform } & \multicolumn{3}{|l|}{ Post-reform } \\
\hline & Discharged & Appropriate & Inappropriate & Discharged & Appropriate & Inappropriate \\
\hline COPD & 9 & 22 & 10 & 16 & 18 & 0 \\
\hline Asthma & 6 & 26 & 20 & 12 & 38 & 0 \\
\hline Bronchiectasis & 0 & 20 & 8 & 13 & 37 & 0 \\
\hline Pneumonia & 4 & 2 & 0 & 11 & 3 & 0 \\
\hline Lung cancer & 5 & 1 & 1 & 6 & 4 & 0 \\
\hline Tuberculosis & 1 & 17 & 1 & 0 & 31 & 0 \\
\hline ILD & 2 & 8 & 8 & 5 & 19 & 0 \\
\hline Other & 1 & 10 & 12 & 15 & & \\
\hline Total & $28(16.1 \%)$ & $85(49.1 \%)$ & $48(27.7 \%)$ & $75(31.3 \%)$ & $161(68.7 \%)$ & $0(0 \%)$ \\
\hline
\end{tabular}

The table shows practice in clinic pre- and post-reform, categorised as discharged or BTS appropriate or inappropriate follow-up.

For conditions where no follow-up guidance is available, these have been merged to a category labeled 'other'.

Totals, shown as $n$ (\%), are given for all patients seen in the study period; detailed breakdowns show $n$ only.

$\mathrm{COPD}=$ chronic obstructive pulmonary disease; ILD=interstitial lung disease. 


\begin{tabular}{|c|c|c|}
\hline & $\begin{array}{l}\text { Pre-clinic } \\
\text { discharge } \\
(n=83)\end{array}$ & $\begin{array}{l}\text { Post-clinic } \\
\text { discharge } \\
(n=55)\end{array}$ \\
\hline Respiratory admissions & 57 & 25 \\
\hline Exacerbation of COPD & 16 & 14 \\
\hline Pneumonia & 12 & 1 \\
\hline Exacerbation of asthma & 11 & 1 \\
\hline Exacerbation of bronchiectasis & 2 & 4 \\
\hline Other respiratory & 6 & 4 \\
\hline Non-respiratory admissions & 26 & 30 \\
\hline \multicolumn{3}{|c|}{$\begin{array}{l}\text { The table shows the number of unscheduled admissions in patients discharged } \\
\text { from clinic for the } 6 \text { months prior to discharge and the } 6 \text { months after discharge } \\
\text { Data are shown as totals for the discharged group. }\end{array}$} \\
\hline \multicolumn{3}{|c|}{$\mathrm{COPD}=$ chronic obstructive pulmonary disease. } \\
\hline
\end{tabular}

reform are shown in Table 3. Overall admissions fell post-reform $(p=0.021)$; this appeared to be driven by a reduction in respiratory admissions, as shown in Table 3.

\section{Effect on patient satisfaction}

A total of 102 patients attending general respiratory clinics in February and March 2012 completed the patient satisfaction survey, of whom 43 were new patients and 59 were follow-up patients. Most patients thought hospital follow-up was valuable: $88 / 102$ (86\%) felt they had a greater understanding of their condition as a result of clinic attendance and 84/102 (82\%) felt that regular clinic attendance improved their compliance with medication; 88/102 (86\%) felt that regular hospital follow-up prevented admission to hospital. Regarding follow-up arrangements, just over half of those who responded expressed a preference for scheduled appointments (53/102; 52\%), with just 23/102 (22\%) expressing satisfaction with open access. The remainder either had no preference or did not know. Fifty-one of 102 (50\%) patients preferred hospital to community care, whilst 30/102 (29\%) were happy with community follow-up.

\section{Effect on referral rates by primary care}

In the initial study period, $2 / 29(6.9 \%)$ and $1 / 111(<1 \%)$ new patients had been seen previously in a respiratory clinic. The mean time between discharge and referral back by primary care was 30 months. In a similar two-week period in June 2012 the proportion of patients being re-referred was $8 / 60$ (13.3\%). One of these patients actually had an open discharge but did not use the facility to telephone to rebook, and another patient was referred for a new respiratory problem unrelated to her previous diagnosis. After exclusion of these patients, the mean time between discharge and re-referral was 21 months. This was a significantly higher refer back rate $(p=0.003)$, although the time to re-referral was no different $(p=0.38)$. It is also notable that the number of new patients had fallen from the peak of the post-reform period; this was in line with a general reduction in new patient referrals to all specialties in our PCT.

Feedback from primary care

We found it difficult to obtain systematic GP feedback about our clinic restructure. Attempts to obtain this via paper questionnaire produced poor results due to extremely low return rates. Formal qualitative analysis of the feedback we did receive could not be undertaken due to the varied format and brief nature of free text responses. However, there are a number of positive points that suggest the system was viewed favourably within local primary care. Firstly, there have been no complaints from GPs or other primary healthcare professionals. Secondly, six local GP practices and community teams have increased the demand for reformed clinic services to such a point that capacity has had to be trebled since the beginning of the redesign. This led to us being approached to develop a service similar to the reformed clinics (to be known as the respiratory ambulatory day service) 5 days a week and this is presently in the set-up phase. We were able to obtain permission for one informative quote from a respondent to request for feedback:

"... I especially appreciate the system of providing the patient with a typed clinical letter and advice ... This also advocates patient empowerment which I fully support. I hope this [service] can continue ..."

\section{Discussion}

\section{Main findings}

We have shown that the BTS criteria ${ }^{2}$ can be implemented to reduce follow-up rates effectively. Our experience suggests that the delivery of a service capable of sustainable management of respiratory LTCs is reliant on a patient-focused multidisciplinary approach, with full consultant engagement in clinic reform processes. This allowed accurate diagnosis and appropriate discharge planning to take place, reduced the number of unnecessary follow-up appointments in secondary care, and reduced unscheduled hospital admissions, thus increasing the quality and value of clinics. However, not all patients were happy with this approach and referrals back to secondary care rose.

\section{Interpretation of findings in relation to previously published work}

New models of healthcare delivery for LTCs are an area of interest at the primary/secondary care interface driven by changes in population structure and healthcare funding. ${ }^{4}$ Integration of primary care, secondary care, and social care, ${ }^{5}$ as well as systems that integrate care for patients with multiple co-morbidities, ${ }^{6}$ are recognised as potential solutions. Long-term follow-up for common conditions usually ends up shifting from secondary to primary care, which may reduce the need for services managing these patients in secondary care and influence how primary care chooses to commission them. Equally, the need to manage acute presentations in community settings as the number of hospital beds falls may require secondary care skills to move to - or at least support services currently viewed as primary care. In the UK these tensions have been managed in some areas by employing respiratory physicians jointly between secondary care and PCTs, but the solution is by no means clear. A report due from the King's Fund late in 2013 (http://www.kingsfund.org.uk/projects/co-ordinated-care-peoplecomplex-chronic-conditions) may assist in this regard. In other countries, such as the USA where private healthcare funding is more widespread, it is more common to have fully integrated systems such 
as that offered by the Veterans Health Administration (VA) or Kaiser Permanente. In Kaiser Permanente, electronic records allow sharing of all data between primary and secondary care doctors, and patients can access their records directly online; this promotes autonomy and self-management at the same time as greater communication and sharing of risk between sectors. The VA have reduced hospital bed use by $50 \%$ and improved care quality in many areas compared with the pre-integrated care period. Meanwhile, organisational reform in primary care across Europe has taken many forms which have been summarised in a report by the European Observatory. ' Some countries allow direct access by patients to secondary care specialists (i.e. patient refers themselves), although this may depend on insurance type; generally this results in greater use of specialists and is more expensive. Themes analysed by the report that are pertinent to this paper include use of financial incentives to change practice and changing professional roles in patient education. In addition, it is recognised that changing the balance between public and private providers and incorporating new communication and information technologies may have a major impact.

In the UK, respiratory conditions account for 24 million consultations in primary care each year; 8 whilst many may be for acute conditions, it is also recognised that GPs and associated allied healthcare professionals (AHPs) provide a greater proportion of chronic care for respiratory conditions than in other countries. ${ }^{9}$ Consequently, UK respiratory medicine represents a good place to study new models of LTC care because the skill set to manage these patients outside secondary care already exists. ${ }^{4}$ We have shown that discharging more patients to primary care does not adversely affect unscheduled care and, in fact, patients seem to attend less often. This could have occurred due to better handover to primary care about management when patients were being discharged and use of some features of an integrated COPD care delivery system (e.g. nurse-led pulmonary rehabilitation referrals), as described in the USA, ${ }^{10}$ but would require further study to determine the cause. Interestingly, the results are in direct contrast with the perceptions of the majority of patients who thought that being seen regularly in clinic prevented admissions.

People with respiratory LTCs value flexible access to a known and trusted professional who can provide or co-ordinate care on their behalf and that of their family or carers. ${ }^{11}$ Traditionally this has been the GP, although increasingly it may be a community AHP. ${ }^{12}$ Patientled secondary care follow-up (open access) is a way in which hospitals can also contribute to this model of care. Specialist oversight of complex COPD was described as an appropriate healthcare delivery model in a recent review. ${ }^{13}$ We managed open access by producing a leaflet describing the concept, which lists the telephone numbers that patients can use to contact us if required. The number takes patients to a respiratory nurse specialist who determines the best follow-up appointment slot if required; many patients did not need to see us but could be diverted to a more appropriate primary care service or managed through telephone advice. Not all patients accepted the concept of open access; only a small proportion reported this as their preference and it failed to be used by one patient in the follow-up dataset. We acknowledge that it may not be appropriate for those with poor self-efficacy ${ }^{14}$ or low educational level who are unable to understand the information given to aid managing their own healthcare. Furthermore, there are recognised variations in the standard of care across the UK for common respiratory LTCS such as COPD, which could have an impact on the success of such a policy. ${ }^{15}$ The BTS guidance continues to emphasise patient choice for hospital follow-up; whether this can be supported as the population ages and finances limit our health economies is a tension that has yet to be resolved.

Open access or standard discharge from hospital outpatients may lead the patient to take more responsibility for selfmanagement. It has been reported previously that guided selfmanagement is done less well in the UK than elsewhere, ${ }^{16}$ a feature we tried to address during the reform process. We therefore gave written advice on how to manage their condition via the hospital letter and by use of patient information leaflets such as those produced by the British Lung Foundation. ${ }^{17}$ This is a well validated strategy in many respiratory LTCs such as COPD. ${ }^{18}$ Most patients felt their understanding of their condition had grown, and the end result of fewer admissions suggests it may have had an impact.

\section{Strengths and limitations of this study}

Our study has some limitations. For example, it is not possible to tell whether there was a true reduction in admissions after discharge or if the figures simply reflect the lack of recurrence or seasonal incidence of conditions such as pneumonia. We do not have detailed surveys of the impact on primary care appointments or referral to specialist community services - this would have been very difficult to obtain and, in the case of respiratory community services, confounded by reorganisation between the initial study period and post-clinic reform follow-up. Whilst there was a rise in the re-referral rate, it is notable that the duration of primary care follow-up without specialist intervention, even in the follow-up period, was close to 2 years. If there was no adverse impact on patient's disease progression and no adverse impact on primary care, the savings to the health economy of reduced hospital follow-up and admissions may still be a valuable outcome. It also validates existing guidance on specialist management policy, ${ }^{2}$ as it is apparent that the majority of patients can be managed in primary care for significant periods of time.

\section{Implications for future research, policy and practice}

Further study to validate our findings in other secondary care settings, extend the work to a wider range of outcomes, and assess the impact on primary care appointments and disease progression is now required.

\section{Conclusions}

Application of the BTS discharge criteria increases discharge rates from respiratory clinics, a feature which many patients dislike, but may be a more efficient use of secondary care resources. Our discharge process focused on self-management advice; this may have been the underlying reason for our observation of decreased use of unscheduled care after the intervention.

Handling editor Niels Chavannes Statistical review Gopal Netuveli 
Acknowledgements We would like to extend thanks to all the patients who contributed opinions to our patient satisfaction survey.

Conflicts of interest The authors declare that they have no conflicts of interest in relation to this article.

Contributorship AMT conducted all data analyses, some data collection, some of the patient satisfaction survey and drafted the manuscript. SD and CS collected data. AT contributed to the patient satisfaction survey. RM conceived the study and supervised the work.

Funding This study received no specific funding. AMT has current funding from the Wellcome Trust, NIHR HTA, Alpha 1 Foundation, UHB charities and Linde REALfund; none of her funders had any input to this study.

\section{References}

1. Department of Health. Equality and excellence: liberating the NHS. London: Department of Health, 2011.

2. British Thoracic Society Standards of Care Committee. BTS statement on criteria for specialist referral, admission, discharge and follow-up for adults with respiratory disease. Thorax 2008;63(Suppl 1):i1-i16. http://dx.doi.org/10.1136/ thx.2007.087627

3. Hospital Outpatient Treatments (HOT) clinics. NHS Innovations South West, 2009.

4. Worth A, Pinnock H, Fletcher M, Hoskins G, Levy ML, Sheikh A. Systems for the management of respiratory disease in primary care - an international series: United Kingdom. Prim Care Respir J 2011;20(1):23-32. http://dx.doi.org/10.4104/ pcri.2010.00070

5. Department of Health. Supporting people with long term conditions: an NHS and social care model to support local innovation and integration. London: Department of Health, 2005.

6. Wright N, Smeeth L, Heath I. Moving beyond single and dual diagnosis in general practice: many patients have multiple morbidities, and their needs have to be addressed. BMJ 2003;326(7388):512-4. http://dx.doi.org/10.1136/ bmj.326.7388.512

7. Saltman RB, Rico A, Boerma WGW, eds. Primary care in the driving seat?
Organisational reform in European primary care. World Health Organisation, 2006.

8. British Thoracic Society. The burden of lung disease. London: British Thoracic Society, 2006.

9. Roberts $N$, Papageorgiou P, Partridge MR. Delivery of asthma and allergy care in Europe. J Asthma 2009;46(8):767-72.

10. Fromer L. Implementing chronic care for COPD: planned visits, care coordination, and patient empowerment for improved outcomes. Int I Chron Obstruct Pulmon Dis 2011;6:605-14. http://dx.doi.org/10.2147/COPD.S24692

11. Kielmann T, Huby G, Powell A, et al. From support to boundary: a qualitative study of the border between self-care and professional care. Patient Educ Couns 2010;79(1):55-61. http://dx.doi.org/10.1016/j.pec.2009.07.015

12. Department of Health. Supporting people with long term conditions: liberating the talents of nurses who care for people with long term conditions. London: Department of Health, 2005.

13. Florez JC. Clinical review: the genetics of type 2 diabetes: a realistic appraisal in 2008. J Clin Endocrinol Metab 2008;93(12):4633-42. http://dx.doi.org/10.1210/jc.20081345

14. Warwick M, Gallagher R, Chenoweth L, Stein-Parbury J. Self-management and symptom monitoring among older adults with chronic obstructive pulmonary disease. J Adv Nurs 2010;66(4):784-93. http://dx.doi.org/10.1111/j.13652648.2009.05238.x

15. George PM, Stone RA, Buckingham RJ, et al. Changes in NHS organization of care and management of hospital admissions with COPD exacerbations between the national COPD audits of 2003 and 2008. QJM 2011;104(10):859-66. http://dx.doi.org/10.1093/qjmed/hcr083

16. Coulter A. Engaging patients in their healthcare: how is the UK doing relative to other countries? Oxford: Picker Institute Europe, 2006.

17. British Lung Foundation. Available from: www.lunguk.org.

18. Rice KL, Dewan N, Bloomfield HE, et al. Disease management program for chronic obstructive pulmonary disease: a randomized controlled trial. Am J Respir Crit Care Med 2010;182(7):890-6. http://dx.doi.org/10.1164/rccm.200910-15790C

\section{Available online at http://www.thepcrj.org}


Appendix 1. Clinic reform manuscript SQUIRE checklist

\section{Title and abstract}

Did you provide clear and accurate information for finding, indexing, and scanning your paper?

a. Indicates the article concerns the improvement of quality (broadly defined to include the safety, effectiveness, patientcenteredness, timeliness, efficiency, and equity of care)

b. States the specific aim of the intervention

c. Specifies the study method used (for example, "A qualitative study," or "A randomized cluster trial")

- Our title reflects the fact that this was a quality improvement project that applied BTS criteria to discharge respiratory outpatients

\section{Abstract}

Summarizes precisely all key information from various sections of the text using the abstract format of the intended publication

- Our abstract meets these criteria for the PCRJ

\section{Introduction}

Why did you start?

Background knowledge - provides a brief, non-selective summary of current knowledge of the care problem being addressed, and characteristics of organizations in which it occurs

Local problem - describes the nature and severity of the specific local problem or system dysfunction that was addressed

- This is detailed in the introduction \& is briefly summarised as follows:

- Reform started due to pressure being placed on respiratory outpatients by restrictions on outpatient funding made by our primary care authority.

- Context of increasing prevalence of LTCs in older population and drive for financial efficiency

- The severity of the problem locally is addressed in our results Intended improvement - describes the specific aim (changes/improvements in care processes and patient outcomes) of the proposed intervention; specifies who (champions, supporters) and what (events, observations) triggered the decision to make changes, and why now (timing)

Study question - states precisely the primary improvement-related question and any secondary questions that the study of the intervention was designed to answer

- This is detailed in the introduction \& is briefly summarised as follows:

- Improvement = implementation of BTS criteria to clinics, aiming to safely discharge more patients, as a result of financial pressures

- Aiming to assess impact $\mathrm{n}$ unscheduled secondary care, referral to clinics and patient satisfaction

\section{Methods}

Ethical issues - describes ethical aspects of implementing and studying the improvement, such as privacy concerns, protection of participants' physical well-being, and potential author conflicts of interest, and how ethical concerns were addressed

Setting -specifies how elements of the local care environment considered most likely to influence change/improvement in the involved site or sites were identified and characterized

Planning the intervention

a. Describes the intervention and component parts in sufficient detail that others could reproduce it

b. Indicates main factors that contributed to choice of the specific intervention

c. Outlines initial plans for how the intervention was to be implemented: e.g., what was to be done (initial steps; functions to be accomplished by those steps; how tests of change would be used to modify intervention), and by whom (intended roles, qualifications, and training of staff)

Planning the study of the intervention

a. Outlines plans for assessing how well the intervention was implemented

b. Describes mechanisms by which intervention components were expected to cause changes, and plans for testing whether those mechanisms were effective

c. Identifies the study design (for example, observational, quasiexperimental, experimental) chosen for measuring impact of the intervention on primary and secondary outcomes, if applicable

d. Explains plans for implementing essential aspects of the chosen study design

e. Describes aspects of the study design that specifically concerned internal validity (integrity of the data) and external validity (generalizability)

Methods of evaluation

a. Describes instruments and procedures (qualitative, quantitative, or mixed) used to assess a) the effectiveness of implementation b) the contributions of intervention components and context factors to effectiveness of the intervention, and c) primary and secondary outcomes

b. Reports efforts to validate and test reliability of assessment instruments

c. Explains methods used to assure data quality and adequacy

Analysis

a. Provides details of qualitative and quantitative (statistical) methods used to draw inferences from the data

b. Aligns unit of analysis with level at which the intervention was implemented, if applicable

c. Specifies degree of variability expected in implementation, change expected in primary outcome (effect size), and ability of study design (including size) to detect such effects

d. Describes analytic methods used to demonstrate effects of time as a variable

- This is detailed in the methods \& is briefly summarised as follows:

- Ethics - data protection ensured by using only clinical team members

o Setting - large teaching hospital OPD

- Planning - Clinic reform process and timeline is described

o How well implanted - comparison of pre/post BTS appropriate follow up rates

o Wider impact - admissions, referral, patient satisfaction 
o Methods of evaluation and statistics - see impact \& statistics sections

- No power calculations are shown as this was an observational study, limited by logistical issues that precluded wider introduction during 2010. There was also no available data on which to base them. Time effects are also not relevant.

o Other points are presented in the discussion section

\section{Results}

Outcomes

a) Nature of setting and improvement intervention

i. Characterizes relevant elements of setting or settings and structures and patterns of setting that provided context for the intervention

- Setting is not detailed any further than in introduction as it was a single Trust

ii. Explains the actual course of the intervention (for example, sequence of steps, events or phases; type and number of participants at key points), preferably using a time-line diagram or flow chart

- See Figure 1

iii. Documents degree of success in implementing intervention components

- See Table 2

iv. Describes how and why the initial plan evolved, and the most important lessons learned from that evolution, particularly the effects of internal feedback from tests of change (reflexiveness)

- No changes were required during the process

b) Changes in processes of care and patient outcomes associated with the intervention

i. Presents data on changes observed in the care delivery process

- See text describing changes in new: follow up ratio and referrals

ii. Presents data on changes observed in measures of patient outcome

- See table 3 and text describing admissions, referrals and patient satisfaction

iii. Considers benefits, harms, unexpected results, problems, failures

- See text describing failures to use open access system

iv. Presents evidence regarding the strength of association between observed changes/improvements and intervention components/context factors

- This is in the discussion, as no direct evidence is available

v. Includes summary of missing data for intervention and outcomes

- One item of missing data on referral source is listed in the text

\section{Discussion}

Summary

a. Summarizes the most important successes and difficulties in implementing intervention components, and main changes observed in care delivery and clinical outcomes

b. Highlights the study's particular strengths

- Covered in first paragraph
Relation to other evidence

Compares and contrasts study results with relevant findings of others, drawing on broad review of the literature; use of a summary table may be helpful in building on existing evidence

- Covered in paragraphs 2-4

Limitations

a. Considers possible sources of confounding, bias, or imprecision in design, measurement, and analysis that might have affected study outcomes (internal validity)

b. Explores factors that could affect generalizability (external validity), for example: representativeness of participants; effectiveness of implementation; dose-response effects; features of local care setting

c. Addresses likelihood that observed gains may weaken over time, and describes plans, if any, for monitoring and maintaining improvement; explicitly states if such planning was not done

d. Reviews efforts made to minimize and adjust for study limitations

e. Assesses the effect of study limitations on interpretation and application of results

- Covered in paragraph 5

Interpretation

a. Explores possible reasons for differences between observed and expected outcomes

b. Draws inferences consistent with the strength of the data about causal mechanisms and size of observed changes, paying particular attention to components of the intervention and context factors that helped determine the intervention's effectiveness (or lack thereof), and types of settings in which this intervention is most likely to be effective

c. Suggests steps that might be modified to improve future performance

d. Reviews issues of opportunity cost and actual financial cost of the intervention

- Outcomes were mostly as expected. Reasons for the positive outcome are discussed in the context of self management of LTCs and open follow up

- Future steps are mentioned in paragraph 5

\section{Conclusions}

a. Considers overall practical usefulness of the intervention

b. Suggests implications of this report for further studies of improvement interventions

- Addressed in paragraph 5 of discussion

\section{Other information}

Were other factors relevant to conduct and interpretation of the study?

- Changes in health service structure are discussed in introduction and limitations sections

\section{Funding}

Describes funding sources, if any, and role of funding organization in design, implementation, interpretation, and publication of study

- N/A 